\title{
Phytoprotection
}

\section{Index des auteurs, volume 88 Author Index, Volume 88}

Volume 88, numéro 3, 2007

La phytoprotection, 100 ans de découvertes!

Phytoprotection: 100 years of discovery

URI : https://id.erudit.org/iderudit/018956ar

DOI : https://doi.org/10.7202/018956ar

Aller au sommaire du numéro

Éditeur(s)

Société de protection des plantes du Québec (SPPQ)

ISSN

0031-9511 (imprimé)

1710-1603 (numérique)

Découvrir la revue

Citer cet article

(2007). Index des auteurs, volume 88. Phytoprotection, 88(3), 113-113.

https://doi.org/10.7202/018956ar d'utilisation que vous pouvez consulter en ligne.

https://apropos.erudit.org/fr/usagers/politique-dutilisation/ 
Index des auteurs, volume 88

Author Index, Volume 88

A-B

Abbas, H.K.

Abbes, Z.

Abu Dieyeh, M.H.

Adamčíková, K.

Attrassi, B.

Attrassi, K.

Avis, T.J.

Bastas, K.K.

Beaulieu, C.

Bélair, G.

Benkirane, R.

Benoit, D.L.

Bilodeau, G.J.

Bissett, J.

Boivin, S.

Bourgeois, G.

Brière, S.C.

Brodeur, L.

\section{C-E}

Carisse, $\mathrm{O}$.

Cartwright, R.D.

Chaïbi, W.

Chamberland, $\mathrm{H}$.

Charest, P.-M.

Coffin, R.H.

Collin, J.

Comeau, A.

Couture, L.

Dauphinais, N.

Desrosiers, J.

Dionne, I.

Douira, A.

Dufault, C.P.

Durand, J.

Estey, R.H.

\section{F-K}

Fournier, Y.

Frégeau-Reid, J.

Gagné, G.

Gilbert, G.

Goettel, M.S.

Gosselin, L.

Gosselin, M.-È.

Hamelin, R.C.

Jabaji-Hare, S.

Jobin, G.

Juhásová, G.

Kabaluk, J.T.

Kharrat, M.

Kobza, M.

Komeil, D.

\section{L-M}

Lacroix, C.

Laflamme. G. $\quad 66$

Lafond, J. $\quad 65$

Lajeunesse, J. $\quad 64,65$

Lanoie, N. $\quad 64$

Laplante, G. $\quad 61$

Le Quéré, $D$. $\quad 64$

Leroux, G.D. $\quad 65$

Libantová, J.

MacDonald, W. 9

Maden, S. $\quad 93$

Maios, C.M.

Meddah, N.

Moravčíková, J. $\quad 27$

Mouria, B. 103

\section{$\mathbf{N}-\mathbf{R}$}

Nyiransengiyumva, C.

Ouazzani-Touhami, A. 57, 103

Ouellette, G.B.

Pageau, D. $\quad 64,65,66$

Parent, S.

Peters, R.D.

Plouffe, D. $\quad 62$

Pouleur, S. $\quad 66$

Rioux, D. $\quad 66,67$

Rochefort, S. $\quad 66$

Roy, G.

\section{S-W}

Savard, L.

Savard, M.

Shier, W.T.

Simao-Beaunoir, A.-M.

Simard, L.

Simard, M.

Simier, P.

Stephenson, P.

Stock, P.S.

Tremblay, M.

Tweddell, R.J.

Vanasse, A.

Vernon, R.S.

Watson, A.K.
67

65

41

64

67

66,67

83

62

67

63

62,65

64

51

61,67 